\title{
UNA IMAGEN DE AFRICA EN EL M.A.N. (MADRID)
}

\author{
FABIOLA SALCEDO GaRCÉS \\ Escuela Española de Historia \\ y Arqueología del CSIC (ROMA)
}

\section{Resumen}

Estudio iconográfico de un aplique en bronce que representa la personificación de la provincia romana de Africa. Procede del área de necrópplis de Baelo Claudia (Bolonia, Cádiz, España) y está conservado en el Museo Arqueológico Nacional (Madrid, España).

\section{Summary}

Iconographical Study of a bronze piece representing the personification of the Roman province of Africa. It was discovered in the necropolis area of Baelo Claudia (Bolonia, Cádiz, Spain) and belongs to the collection of the Museo Arqueológico Nacional (Madrid, Spain).

La pieza que se presenta a continuación es un aplique en bronce procedente de la ciudad romana de Baelo Claudia (Bolonia, Cádiz) y actualmente conservado en el Museo Arqueológico Nacional de Madrid (n. ${ }^{\circ}$ Inv.: 26-15-74). Tras dos breves notas emitidas, una a raíz de su descubrimiento y otra con motivo de su ingreso en el Museo (Rivero 1927, p. 53, n.o 441, fig.59) fue, por primera vez, puesta al acceso del gran público en la exposición "Los Bronces romanos en España" que tuvo lugar en Madrid, en 1990 (Bronces Romanos 1990, p. 268, n. $\left.{ }^{\circ} 198\right)^{1}$.

El aplique, de forma cóncava y tamaño reducido (Dimensiones: 4,2 × 4,7 × 2,5 cms.; peso, 1,5 grs.), representa la cabeza de la personificación de la provincia romana de Africa según su tipo icono-

1 Vease también el artículo de Rodriguez ()liva, P., "Los bronces de la Bética y la Lusitania", en Bronces Romanos 1990 , p. $91-102$. 
gráfico básico: figura femenina tocada con las exuviae elephantis (el colmillo de la izquierda está parcialmente mutilado). Este atributo, de raigambre helenística, es portador de un claro mensaje político capaz de legitimar a cualquier facción o individuo que aspire a establecer su poder en la región ${ }^{2}$. La primera vez que aparece asociado a una natio o pueblo africano es con las monedas del reino númida de Hiarbas, en el 108 a.C. ${ }^{3}$. Pero, más tarde, también Roma sabrá apreciar el valor ratificante del motivo y lo adoptará, convirtiéndolo, desde entonces, en signo distintivo de la provincia ${ }^{4}$.

El interés de la pieza que tratamos en estas páginas reside en dos aspectos fundamentales: uno, el constituir una de las escasas representaciones de la provincia romana de Africa en la Península ${ }^{5}$; dos, el haber aparecido en un contexto funerario.

Aunque la crónica del descubrimiento de esta cabecita es bastante parca en detalles, sabemos que salió a la luz en el curso de la excavaciones de 1926 llevadas a cabo por P. Paris en Baelo Claudia. La memoria de excavación sólo nos ha transmitido que apareció en la necrópolis, junto a las urnas funerarias y como parte de un ajuar integrado por un gran fragmento de cristal de roca, algunas conchas marinas y otro aplique en forma de máscara cómica (Paris 1926, p. 118, fig. 67, p. 189, Pl. XXXIII).

Para analizar el carácter de la pieza, hay que tener presente la función original y la añadida. En cuanto aplique mobiliar, su papel sería principalmente ornamental, como ocurre con otras muchas representaciones de Africa. Pensemos, por ejemplo, en los apliques de procedencia africana conservados en el Museo del Louvre (n.o Inv.: 4174; Sauer 1964, p. 153, n.o 1, taf. 52, 4,53, 1-2., o en el Museo Británico (n. ${ }^{\circ}$ inv.: 1935; Sauer 1964, p. 153, n. ${ }^{\circ}$ 2, taf. 53, 4. Pero, por otra parte, su inclusión como objeto de ajuar en una tumba confiere a la pieza una función añadida que sería la de recordatorio de la tierra de origen o quizá la de amuleto.

Hay que tener en cuenta, además, que la personificación de Africa era algo más que un recurso iconográfico y artístico para evocar una provincia. Por distintas fuentes literarias antiguas ${ }^{6}$ sabemos que Africa gozaba de un cierto sentido religioso que, aunque ambiguo, le permitía estar presente en templos y santuarios. Sabemos, por ejemplo, que la cabeza en mármol, procedente de Lambaesis (Lambése, Museo Municipal, Argelia; Leglay 1966, p. 1236, fig.6) estuvo situada originariamente en una de las tres cellae de un templo próximo a la vía que unía el campamento de la III Legión Augustea con el Capitolio de la ciudad ${ }^{7}$. También poseemos testimonios de que la figura de Africa sirvió para acompañar, en contextos funerarios, a aquellos individuos de origen africano que deseaban tener cercana la imagen personificada de su tierra natal. Es el caso de la terracota hallada en la necrópolis de

\footnotetext{
${ }^{2}$ Sobre el origen iconográfico de la personificación de Africa, ver Salcedo,F., "La iconografía de Africa en época romana: algunos aspectos". ArchEspA, 64, 1991, pp. 284-292: Idem . "La iconografia de la provincia romana de Africa", Bibliotheca Italica. Monografias de la Escuela Española de Historia y Anqueologia en Roma, n.० 21 (en prensa).

${ }^{3}$ Museo Británico, Londres; col. particular; Cabinet des Medailles, Paris. Mazard 1955, p. 54, n. • 94,95,97,98.

4 Au- Pompeyo- Roma, 71 a.C., BMCRR II, p. 464,n.•20; III, tau CX,n.・13

5 Otra representación hallada en suclo peninsular es un fragmento de lucerna procedente de la factoría de salazones de Almuńćcar y fabricada en Mauritania Tingitania. Almuñécar, Museo Arq. Municipal. (Êpoca flavia), ver Molina,F., Almuñécar. Arqueologia e Historia II, Granada 1983. pp. 210-212, n. 23. 2)

${ }^{6}$ Plinio, HN. 28, 5, 24, "...in Africa nemo destinat aliquid nisi prafatus A fricam, in ceteris vero gentibus deos ante obtestatur ut velint", ("En Africa, nadie decide algo sin decir primero "Africa", mientras que en otros pueblos se hacen muchos rezos para conseguir la aprobación de los dioses"). (locb, cd., W.H.S. Jones, 1963)

7 Sobre el origen oriental de la triple cellae en los templos, característica frecuente en el Africa romana, ver Pensabene, P., "Archittetura e decorazione architettonica nell'Africa Romana", Atri VI Convegno L'Africa Romana, Sassari 1988, p. 434, n. 8.
} 
Via Portuense, en Roma ${ }^{8}$, o de la urna cineraria de Sextus Caesonius Apollonius (Roma, Museos Vaticanos, Galería Lapidaria) (Amelung 1903, n.o 34b), ambas piezas fechadas en el s. I d.C.

Casos similares pueden ser los de otros bronces, como el busto de Berrovaghia (Argel, Musée des Antiquités, Argelia; Leglay 1981, 252,n. ${ }^{\circ} 22$, la estatuilla de Lambaesis (Argel, Musée des Antiquités, Argelia; Leglay 1981, 253, n. ${ }^{\circ}$ 38), o la de Carnuntum (Kärntem, Carnumtinum Museum, Austria. N. ${ }^{\circ}$ Inv.: 11933; Fleischer 1967, p. 95, n.o 115, taf. 61, que pudieron haber pertenecido a un larario.

Por otra parte, en lo que concierne al lugar de hallazgo, no es de extrañar que aparezca en Hispania un amuleto con la representación de Africa dada la secular relación existente entre el norte de Africa y la zona peninsular del estrecho.

En cuanto a la datación de la pieza, dado que no poseemos datos fidedignos de la excavación, sólo podemos extraer conclusiones a través del estilo de ejecución. A este respecto, hay que observar que, a pesar de la cierta tosquedad de las facciones del rostro -labios carnosos, nariz ancha, ojos almendrados, cejas marcadas -, la disposición del cabello, en mechones ligeramente ondulados y paralelos, sugiere una cronología que apunta hacia el s. I d.C., como ocurre con los apliques del Museo del Louvre y del Museo Británico, ya mencionados. La trepanación de las pupilas indica que pudieron estar rellenas de pasta vitrea. La pieza gaditana es claramente obra de un taller local africano - quizá el de Lambaesis - donde se copiarían originales producidos en talleres itálicos.

\section{BIBLIOGRAFIA ABREVIADA}

AMELUNG, W.: Die Skulpturen des Vatikanischen Museum, 1903.

BronCes Romanos, 1990: Los Bronces romanos en España, Catálogo de la Exposición. Madrid 1990.

FLEISCHER, R.: Die römischen Bronzen aus Osterreich, Mainz 1967.

LEGLAY, M.: "Encore la Dea Africa", Mel.A.Piganiol3, 1966, 1233-1239.

- LIMC I, s.v. Africa, 1981.

PARIS,P.: Fouilles de Bélo, tomo II, Burdeos 1926.

RIVERO,C. M.': Los Bronces Antiguos del Museo Arqueológico Nacional. Catálogo ilustrado de los objetos que se exponen en la sala IV, Toledo 1927.

SAUER, H.: "Das Motiv nachalexandrinischer Köpfe mit Elefanten-Exuvie", Festschrift Eugen v. Mercklin, 1964.

${ }^{8}$ Aparecida junto a una estatuilla de Harpocrates y otra que representa una divinidad femenina oriental, ver Leglay 1981 , p. 253, n.०37. 